Received: 2020-07-18

\title{
In vitro clonal propagation and efficient acclimatization with use of hydrogel of intensively sweet medicinal plant Lippia dulcis Trev.
}

\author{
MAGDALENA TOMASZEWSKA-SOWA®
}

University of Science and Technology

Department of Agricultural Biotechnology

Bernardyńska 6

85-029 Bydgoszcz, Poland,

phone: + 485237495 21; e-mail: magda@utp.edu.pl

\section{Summary}

Introduction: The leaves of Lippia dulcis contain high amounts of hernandulcin. It is one thousand fold sweeter than sucrose, however, it hardly contains any calories.

Objective: The aim of this research was to optimalisation of micropropagation and acclimatization of $L$. dulcis.

Methods: The nodal explants were inoculated on phytohormone-free MS medium. After 6 weeks the explants were inoculated onto the MS medium with different plant growth regulators. Well-developed rooted plantlets were adapted to ex vitro conditions using hydrogel.

Results: On the medium with BAP and NAA the highest number of shoots were produced. The higest average shoot length, number of the leaves and the leaf area were recorded on the medium with $\mathrm{GA}_{3}$. Adding IBA increased the number of roots. The addition of hydrogel enhanced the acclimatization efficiency.

Conclusions: There was observed a positive, stimulating influence of growth regulators on mass propagation and increase in the number of leaves and the leaf area and influence of hydrogel on the development of plantlets during acclimatization.

Key words: phytohormones, hydrogel, Lippia dulcis, micropropagation, rooting

Słowa kluczowe: fitohormony, hydrożel, Lippia dulcis, mikrorozmnażanie, ukorzenianie 


\section{INTRODUCTION}

An intensive development of civilization as well as an easy and quick access to synthetically produced drugs and healthy substances have outclassed the benefits of natural products. The active compounds in plants are often equal to their chemical equivalents in terms of potency. Furthermore, their proper application ensures a reaction effectiveness with no negative side effects. Lippia dulcis Trev. (Phyla scaberrima, Lippia scaherrima, Zapania scaberrima) is one of such traditional natural medicinal plants of Verbenaceae family. It is up to $40 \mathrm{~cm}$ tall and its white flowers produce an intensive aroma. Long plant shoots end with leaflets dark green in colour, sometimes changing into violet. They creep spectacularly on the ground. Lippia comes from the tropical sites and is popular in Asia and South America. The first reports on $L$. dulcis come from 1552 when its sweet leaf taste was discovered. It is due to the fact that the leaves contain high amounts of edible sweetening substance, hernandulcin, an organic chemical compound of the terpenoids group, analog of bisabolol. It is one thousand fold sweeter than sucrose, however, it hardly contains any calories [1-3]. In some Asian countries, $L . d u l-$ cis has been added to desserts, used for sweetening tea or to provide flavour of water. It can be used as a sweetener, although it is sensitive to high temperatures. From the leaves of Lippia dulcis also verbascoside (kusaginin, acteoside) was extracted, a phenolic compound and a very strong antioxidant, showing anti-inflammatory and pain-relieving, immunosuppressive, immune modeling, anticancer and hepatoprotective properties [4] (fig. 1). In folk medicine, L. dulcis has been used in the treatment of bronchitis, cough, indigestion, liver disorders, hypertension, and dysentery. L. dulcis shows a specific aroma as a result of camphor oil found in its tissues. For that reason people, especially children and pregnant women, should not consume high amounts of fresh leaves. Due to numerous active substances in tissues, L. dulcis, as demonstrated by the pharmacological and biochemical studies so far, shows antioxidative, anti-inflammatory and antibacterial properties towards Salmonella typhi and Shigella flexneri, Staphylococcus aureus, Streptococcus pneumoniae, Vibrio cholerae $[1,2,5]$. In addition, Abe et al. [6] found that the L. dulcis extracts had significant antiproliferative effects on several lines of human cancer cultures. Despite its health-boosting properties the plant is not popular a lot.

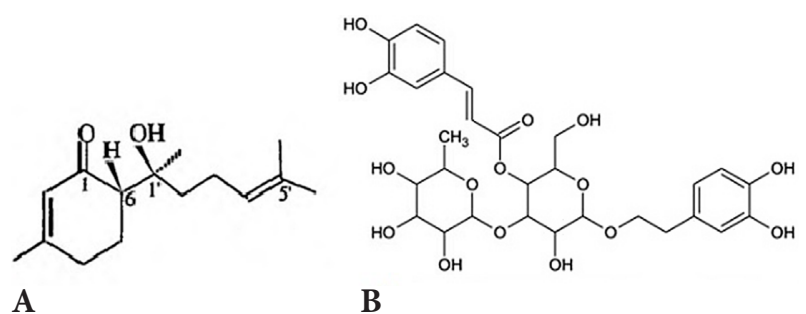

Figure 1.

Hernandulcin (a), verbascoside (b)

In vitro methods of propagation and callus formation of plants of the Verbenaceae family have been described quite extensively. However, there are very few articles about $L$. dulcis in vitro propagation. Urrea et al. 2009 [7] indicate the possibility of using shoot tips and nodal segments for micropropagation and induction of callus formation. The shoot cultures and hairy root cultures of $L$. dulcis have been used as a source of hernandulcin, which is sweeter than sucrose and can be found in human diet $[8,9]$. In the present study we evaluate the effect of different plant growth regulators on shoot and leaf induction, regeneration and rooting of $L$. dulcis and propose an optimal system of acclimatization of this species to ex vitro conditions.

\section{MATERIAL AND METHODS}

\section{The initiation of culture and disinfection of plant material.}

Explants of $L$. dulcis were collected from ex vitro plants growing in greenhouse conditions (fig. 2, 3A). Nodal fragments without leaves, $1.5-2.0 \mathrm{~cm}$ in length, were chemically disinfected. At the first stage, the vegetable parts, rinsed with running tap water, were immersed for 1 minute into a 70\% EtOH solution for degreasing, degassing, and surface disinfection. Then the explants were treated with $10 \%$ calcium hypochlorite $\left(\mathrm{Ca}\left(\mathrm{OCl}_{2}\right)\right)$ solution with 3 drops of Tween 20 for 15 minutes. Finally shoot parts were rinsed three times with sterile distilled water. The sterilized nodal explants were inoculated on phytohormone-free $\mathrm{Mu}-$ rashige and Skoog medium (MS) [10] supplemented with $3 \%$ sucrose and solidified with $0.8 \%$ agar (fig. 3B). The medium was adjusted to $\mathrm{pH} 5.7$ and autoclaved at $0.5 \mathrm{MPa}$ at $121^{\circ} \mathrm{C}$ for 25 minutes. The cultures were carried out in a plant growth chamber under a 16-hour photoperiod with the light intensity of $40 \mu \mathrm{mol} \cdot \mathrm{m}^{-2} \mathrm{~s}^{-1}$ and the temperature of $25 \pm 2^{\circ} \mathrm{C}$. The number of shoots initiated per explant were recorded. 


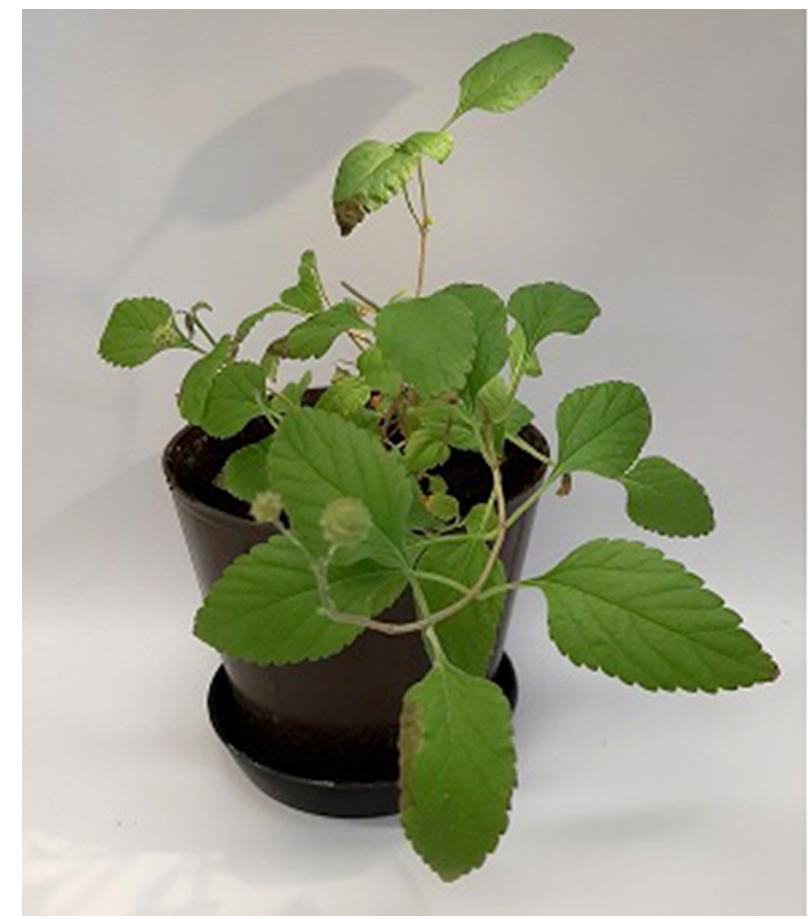

Figure 2.

Ex vitro plants of Lippia dulcis growing under greenhouse conditions

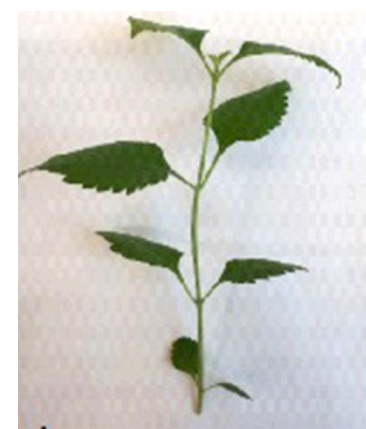

A
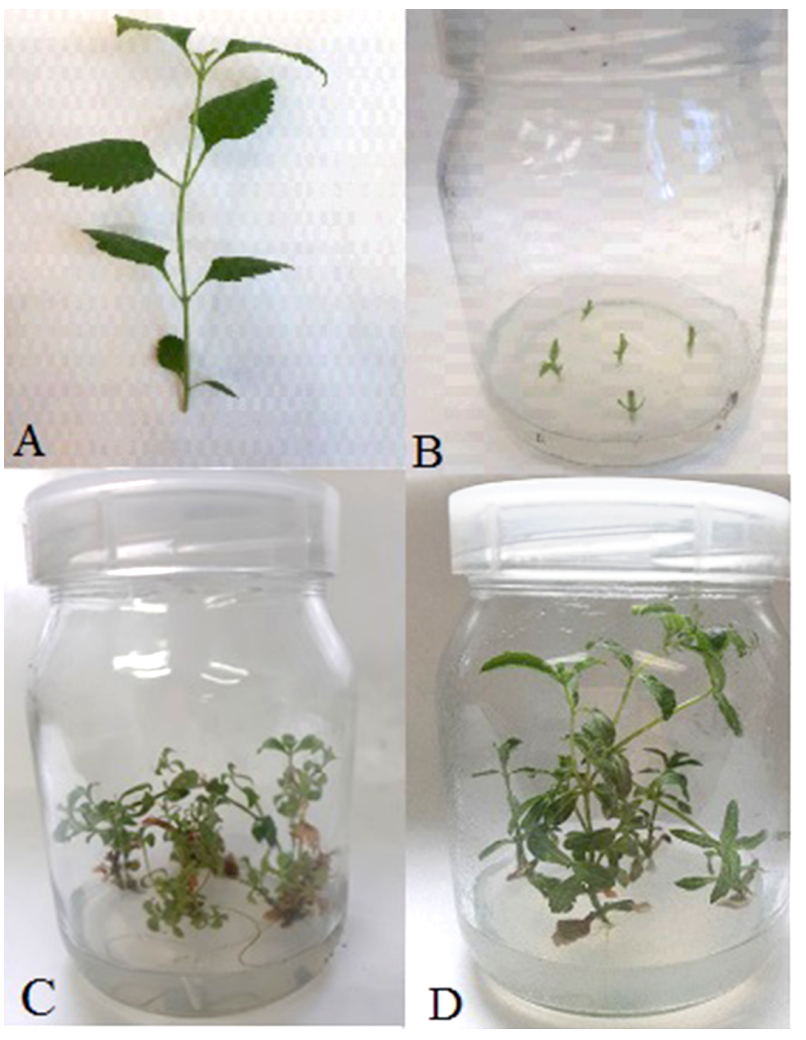

Figure 3.

Different stages in the micropropagation of Lippia dulcis: fragment of Lippia dulcis ex vitro shoot (A), initiation of shoot formation on the MS medium (B), secondary explants (C), root induction (D)

\section{Shoot proliferation process}

After 6 weeks of shoot culture, individual plants were selected and cut into nodal fragments with one bud of maximum $2 \mathrm{~cm}$ in length. The explants were inoculated onto MS medium with different concentrations and combinations of BAP (6-benzylaminopurine, Sigma - Aldrich, Germany) and NAA (naphthaleneacetic acid, Sigma - Aldrich, Germany) and $\mathrm{GA}_{3}$ (gibberellic acid, Sigma - Aldrich, Germany) (Table 1) and incubated under such growth conditions (Fig. 3C). For each replication of the experiment 50 explants were used and the experiment was repeated three times. After 8 weeks the newly-formed shoots were counted and the mean shoot length was recorded. The results were subjected to statistical analysis and the proliferation rate was determined.

\section{Rooting of elongated shoots}

After 8 weeks, the amplified axillary shoots which regenerated on the medium with the addition of $1.0 \mathrm{mg} \mathrm{dm}^{-3} \mathrm{BAP}$ and $1.0 \mathrm{mg} \mathrm{dm}{ }^{-3} \mathrm{NAA}$ were transferred onto the rooting MS medium (fig. $3 \mathrm{D})$. As a rooting growth medium a solid MS medium without any growth regulators as well as an MS medium supplemented with $0.5 \mathrm{mg} \mathrm{dm}^{-3} \mathrm{IBA}$ (indole-3-butyric acid, Sigma - Aldrich, Germany) or $0.5 \mathrm{mg} \mathrm{dm}^{-3}$ IAA (indole-3-acetic acid, Sigma - Aldrich, Germany) were used. After the successive 8 weeks the following parameters were evaluated: the percentage roots, the root number and the length of roots (fig. 4).

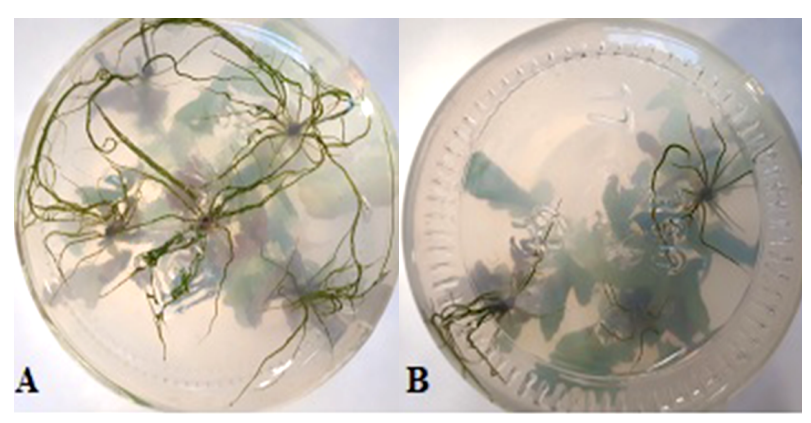

Figure 4.

Effect of IBA (A) and MS free medium (B) on in vitro rooting of shoots in Lippia dulcis 
Table 1.

Effect of plant growth regulators on shoot and leaf induction and regeneration

\begin{tabular}{|c|c|c|c|c|c|c|}
\hline \multicolumn{3}{|c|}{$\begin{array}{l}\text { Plant growth regulator } \\
\left(\mathrm{mg} \mathrm{dm}^{-3}\right)\end{array}$} & \multirow{2}{*}{$\begin{array}{l}\text { Average number } \\
\text { of shoots/explant } \\
\text { (mean } \pm \mathrm{SD})\end{array}$} & \multirow{2}{*}{$\begin{array}{l}\text { Average shoot } \\
\text { length }(\mathrm{cm}) \\
\text { (mean } \pm \mathrm{SD})\end{array}$} & \multirow{2}{*}{$\begin{array}{c}\text { Average no. of leaves } \\
\text { per shoot } \\
(\text { mean } \pm \text { SD })\end{array}$} & \multirow{2}{*}{$\begin{array}{c}\text { Average leaf area } \\
\qquad\left(\mathrm{cm}^{2}\right) \\
(\text { mean } \pm \mathrm{SD})\end{array}$} \\
\hline BAP & NAA & $\mathrm{GA}_{3}$ & & & & \\
\hline- & - & - & $2.02 \pm 0.80 c$ & $3.06 \pm 1.23 \mathrm{c}$ & $3.96 \pm 0.8 b$ & $0.86 \pm 0.13 \mathrm{~ns}$ \\
\hline 0.5 & - & - & $2.14 \pm 0.85 b c$ & $3.94 \pm 1.58 \mathrm{bc}$ & $3.44 \pm 1.23 b$ & $0.81 \pm 0.21 \mathrm{~ns}$ \\
\hline 1.0 & - & - & $2.26 \pm 0.94 b c$ & $3.80 \pm 1.56 \mathrm{bc}$ & $3.54 \pm 1.09 \mathrm{~b}$ & $0.89 \pm 0.20 \mathrm{~ns}$ \\
\hline 0.5 & 1.0 & - & $4.08 \pm 1.19 \mathrm{ab}$ & $4.42 \pm 1.67 \mathrm{~b}$ & $3.74 \pm 0.95 b$ & $1.0 \pm 0.31 \mathrm{~ns}$ \\
\hline 1.0 & 1.0 & - & $5.14 \pm 0.99 \mathrm{a}$ & $4.07 \pm 1.76 \mathrm{~b}$ & $4.04 \pm 1.04 \mathrm{~b}$ & $0.95 \pm 0.25 \mathrm{~ns}$ \\
\hline 0.5 & - & 1.0 & $3.42 \pm 1.31 \mathrm{~b}$ & $5.34 \pm 1.82 \mathrm{a}$ & $4.40 \pm 1.64 \mathrm{ab}$ & $0.92 \pm 0.26 \mathrm{~ns}$ \\
\hline 1.0 & - & 1.0 & $3.72 \pm 1.32 \mathrm{~b}$ & $5.02 \pm 1.73 \mathrm{ab}$ & $4.60 \pm 1.57 \mathrm{a}$ & $0.90 \pm 0.17 \mathrm{~ns}$ \\
\hline 0.5 & 1.0 & 1.0 & $4.80 \pm 0.95 \mathrm{a}$ & $5.66 \pm 1.82 \mathrm{a}$ & $4.70 \pm 1.63 \mathrm{a}$ & $0.98 \pm 0.11 \mathrm{~ns}$ \\
\hline 1.0 & 1.0 & 1.0 & $4.34 \pm 1.09 \mathrm{a}$ & $6.26 \pm 1.35 \mathrm{a}$ & $5.40 \pm 1.17 \mathrm{a}$ & $1.02 \pm 0.11 \mathrm{~ns}$ \\
\hline
\end{tabular}

Results are mean \pm SD (standard deviation); means followed by the same letter do not differ significantly at $\alpha=0.05$

\section{Acclimatization of plantlets}

Well-developed rooted plantlets were adapted to $e x$ vitro conditions. The plants were removed from the jars and thoroughly washed with water and transferred to plastic pots. The pots were filled with sterilized substrate in two variants: a mixture of sand, soil and vermiculite (2:1:1) and a mixture of sand, soil, vermiculite and hydrogel (1:1:1:1), with $\mathrm{pH}$ ranging from 5.5 to 6.5. They were placed in the growth chamber with the light intensity of $40 \mu \mathrm{mol} \cdot \mathrm{m}^{-2} \mathrm{~s}^{-1}$ and the temperature of $25 \pm 2^{\circ} \mathrm{C}$ under a 16 -hour photoperiod. After 28 days of adaptation to ex vitro conditions, the plants were transferred to greenhouse conditions.

\section{Statistical analyses}

The results on the number of shoots per explant, leaf number and leaf area as well as on the root length and number were subjected to statistical analyses. The statistical analyses comprised the analysis of variance and the significance of differences between means, verified with the Tukey test at significance level of $\alpha=0.05$. The analyses of variance were performed using the Statistica software.

Ethical approval: The conducted research is not related to either human or animal use.

\section{RESULTS AND DISCUSSION}

As for bacterial and fungal control, the combination of alcohol and calcium hypochlorite yielded $78 \%$ of axenic cultures. Three hundred sterilized nodal segments produced 234 sterile shoots. Stems emerging from lateral buds demonstrated a normal plant habit: they were green in colour, with no signs of destructive impact of the active substance used in the process of sterilization. After 6 weeks of nodal fragments culture, along with at least one lateral bud derived from in vitro, the cultures were used as secondary explants for shoot proliferation. Urrea et al. 2009 [7] also used the shoot tips and nodal segments of $L$. dulcis for micropropagation and callus formation. This kind of explant was offered as the best explant for in vitro proliferation and reported by Boustani et al. [11], Juliani et al. [12], and Castellanos-Hernandez et al. [13]. As it was noted by Servin et al. [14], the nodal explants on the half MS medium with no growth regulator has been the best in forming sprouts and roots from buds. Similarly, Urrea et al. 2009 [7] considered the MS medium without growth regulators to be the most effective for induction and multiplication of $L$. dulcis shoots from shoot tips and nodal segments. In another study of in vitro propagation in plant species of the Verbenaceae family it was detected that nodal segments on the medium supplemented with BAP and NAA induced multiple shoots [15]. In present experiment, the explants were inoculated on the modified MS medium to proliferate and to grow shoots. Over successive 10 weeks, the number and length of shoots were estimated, the number of leaves was determined and the width of the leaf blade - measured. Among the plants originating from different variants of the experiment, the medium supplemented with $1.0 \mathrm{mg} \mathrm{dm}^{-3} \mathrm{BAP}$ and $1.0 \mathrm{mg} \mathrm{dm}^{-3}$ NAA produced the highest number of 
shoots from a single explant (approximately 5.14). This combination of phytohormones also triggered the highest multiple shoots response in Lippia filifolia [15]. In the micropropagation of Lippia junelliana, an increase in the number of shoots was observed with an increase in BA concentration. The best results were achieved by combining $\mathrm{BA}$ $(4.4 \mu \mathrm{M})$ and IBA $(0.04 \mu \mathrm{M})$ [12], whereas other researchers reported the highest number of shoots per explant of Lippia graveolens from the medium with BAP only. The best results were obtained in the medium containing $2 \mathrm{mg} \mathrm{dm}^{-3} \mathrm{BA}$, less shoots and roots were formed when there were lower concentrations of $\mathrm{BA}$ or $\mathrm{BA}$ in combination with auxin in the medium [13]. In the presence of another phytohormone from the auxin group - 2,4-D at a concentration of $0.1 \mathrm{mg} \mathrm{dm}^{-3}$ Urrea et al. 2009 [7] obtained intensive callus formation on explants isolated from L. dulcis plants. In our experiment, short internodes of $L$. dulcis plants growing on culture media, containing BAP or NAA were observed. To produce longer internodes, $\mathrm{GA}_{3}$ was applied following [16]. The presence of $\mathrm{GA}_{3}$ in the medium enhanced the length of shoots and the number of leaves per shoot after 10 weeks of cultivation. The longest shoots $(6.26 \mathrm{~cm})$ were produced on the medium supplemented with $1.0 \mathrm{mg} \mathrm{dm}^{-3} \mathrm{BAP}, 1.0 \mathrm{mg} \mathrm{dm}^{-3} \mathrm{NAA}$ and $1.0 \mathrm{mg} \mathrm{dm}^{-3} \mathrm{GA}_{3}$, while only cytokinins and auxins in the same concentrations without $\mathrm{GA}_{3}$ resulted in shorter shoots $(4.07 \mathrm{~cm})$. The effect of gibberellic acid on shoot elongation was also reported by Rani and Nair [17]. In in vitro micropropagation of Vitex negundo, the elongation of shoots was observed on the MS medium containing $2.4 \mathrm{mM} \mathrm{GA}_{3}$ [17]. The number of the leaves formed and the leaf area also depended on the phytohormonal composition of the medium. With $\mathrm{GA}_{3}$ in the medium, the highest number of leaves per shoot and the largest leaf area were noted. The highest number of leaves (5.4) per shoot was observed on the medium with BAP, NAA and $\mathrm{GA}_{3}\left(1.0 \mathrm{mg} \mathrm{dm}^{-3}\right)$. In that case the biggest leaf area $\left(1.02 \mathrm{~cm}^{2}\right)$ it was also reported (tab. 1).
After four weeks of culture, the regenerated shoots were transferred to the rooting media. Root initiation was observed within three weeks of culture. The highest rooting rate and root length were produced on the medium supplemented with $0.5 \mathrm{mg} \mathrm{dm}{ }^{-3}$ IBA. For that species, the addition of IBA to induce rhizogenesis increased the number of roots per explant significantly (by about 50\%), as well as they were about $53 \%$ longer (tab. 2). Adding IBA significantly increased the number and the length of the roots described also in the studies of Castellanos-Hernandez et al. [13]. According to them, best results were obtained in medium containing $1.5 \mathrm{mg} \mathrm{dm}^{-3} \mathrm{IBA}$. In the presence of this phytohormone, an average of 15 roots per shoot with a length of up to $10 \mathrm{~cm}$ was obtained. Similarly, Boustani et al. [11] reported root formation when exposed shoots to auxin in the medium. When medium were supplemented just with cytokinins without combination of auxin regenerated shoots were not rooted. The authors described only the formation of shoots and leaves from the callus. Much research on the Verbenaceae family reports on the root development in plants of that family to be very easy, however, some report observed the highest rooting percentage on the MS free medium. Moreover, a treatment without growth regulators produces a large and vigorous root system [12].

The effectiveness of water use in the acclimatization process is important for the improvement of the survival and performance of plant plantlets. Water absorbed by a hydrogel (superabsorbent polymer) has the potential to reduce drought stress after planting and it can extend the survival time of plantlets by approximately $50 \%$, as compared with the plantlets without hydrogel in soil [18]. A total of 200 plantlets were placed in controlled conditions. To improve the process of acclimatization, two variants of substrate were analysed. As the results show, the mixture of sand, soil, vermiculite and hydrogel (1:1:1:1) increased the acclimatization efficiency, a $43.3 \%$ increase as compared with the mixture of sand, soil and vermiculite (2:1:1) (fig.5). A positive influence

Table 2.

Effect of IBA and IAA on in vitro root induction in Lippia dulcis

\begin{tabular}{cccc}
\hline $\begin{array}{c}\text { Plant growth regulator } \\
{\left[\mathrm{mg} \mathrm{dm}^{-3}\right]}\end{array}$ & Root induction [\%] & $\begin{array}{c}\text { Average number of roots/ } \\
\text { shoot [mean } \pm \text { SD] }\end{array}$ & $\begin{array}{c}\text { Average root length [cm] } \\
{[\mathrm{mean} \pm \mathrm{SD}]}\end{array}$ \\
\hline 0 & $100.0 \pm 0.0 \mathrm{a}$ & $8.40 \pm 1.73 \mathrm{c}$ & $2.90 \pm 0.41 \mathrm{~b}$ \\
\hline $0.5 \mathrm{IBA}$ & $100.0 \pm 0.0 \mathrm{a}$ & $12.65 \pm 1.87 \mathrm{a}$ & $4.45 \pm 0.96 \mathrm{a}$ \\
\hline $0.5 \mathrm{IAA}$ & $97.0 \pm 0.4 \mathrm{~b}$ & $10.20 \pm 1.51 \mathrm{~b}$ & $2.85 \pm 0.73 \mathrm{~b}$ \\
\hline
\end{tabular}

Results are mean \pm SD (standard deviation); means followed by the same letter do not differ significantly at $\alpha=0.05$ 
of hydrogel on plant development of plantlets during acclimatization was also observed by El-Asmar et al. [19]. The hydrogel improves fresh and dry aboveground biomass in corn by $25 \%$ and it prolongs the survival time of pine plantlets by $90 \%$. According to Wang and Boogher [20], hydrogels absorb various amounts of water during expansion and have been found to increase water retention in potting media, thus reducing the irrigation frequency and delaying the onset of wilting. Adding hydrogel to soil demonstrated a positive impact on the development of argan seedling parameters [21], it significantly enhanced growth, root collar diameter and the slenderness index of plants. The biodegradable superabsorbent cellulose-based hydrogel used by Montesano et al. [22] for sweet basil plants grown on perlite with hydrogel added showed an increase in fresh biomass.

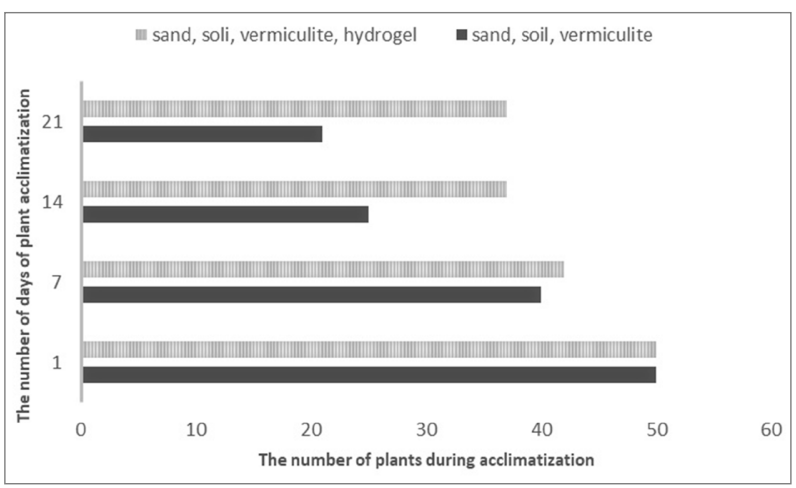

Figure 5.

Effectiveness of acclimatization of plants depending on the type of substrate used

\section{CONCLUSIONS}

Our study demonstrates that the MS medium supplemented with BAP and NAA is useful for mass propagation of $L$. dulcis. $\mathrm{GA}_{3}$ application to the medium in in vitro culture stimulates plant growth and triggers an increase in the number of leaves and the leaf area. The process of rooting was stimulated by the presence of IBA in the medium. A positive influence of hydrogel on the development of plantlets during acclimatization was observed. The mixture of sand, soil, vermiculite and hydrogel increased the acclimatization efficiency. The method can be used for the production of plants on a commercial scale. Plants from in vitro cultures can be a source of plantlets for planting organic crops and for home gardens.

Conflict of interest: Authors declare no conflict of interest.

\section{REFERENCES}

1. Compadre CM, Hussain RA, Compadre RLL, Pezzuto JM, Kinghorn AD. The intensely sweet sesquiterpene hernandulcin: isolation, synthesis, characterization, and preliminary safety evaluation. J Agric Food Chem 1987; 35:273-279.

2. Souto-Bachiller FA, de Jesus-Echevarria $M$, Cárdenas-González OE, Acuna-Rodriguez MF, Meléndez PA, Romero-Ramsey L. Terpenoid composition of Lippia dulcis. Phytochemistry 1997; 44(6):1077-1086.

3. de Oliveira PF, Machado RAF, Bolzan A, Barth D. Supercritical fluid extraction of hernandulcin from Lippia dulcis Trev. J Supercrit Fluids 2012; 63:161-168. doi: http://dx.doi.org/10.1016/j.supflu.2011.12.003

4. Wilczańska-Barska A, Chmura B, Krauze-Baranowska M. Akteozyd - fenylopropanoid o cennych właściwościach farmakologicznych [Acteoside - phenylpropanoid with valuable pharmacological activities]. Post Fitoter 2010; 3:157-161 [in Polish].

5. Kaneda N, Lee IS, Gupta MP, Soejarto DD, Kinghorn AD. (+)-4-hydroxyhernandulcin, a new sweet sesquiterpene from the leaves and flowers of Lippia dulcis. J Nat Prod 1992; 55:1136-1141.

6. Abe F, et al. Trypanocidal constituents in plants 1. Evaluation of some Mexican plants for their trypanocidal activity and active constituents in guaco, root of Aristolochia taliscana. Biol Pharm Bull 2002; 25:1188-1191.

7. Urrea A, Castrillon P, Monsalve Z. In vitro propagation and tisular diferentiation in Lippia dulcis. Actual Biol 2009; 31(9):21-29.

8. Sauerwein M, Flores H.E, Yamazaki T, Shimomura K. Lippia dulcis shoot cultures as a source of the sweet sesquiterpene hernandulcin. Plant Cell Rep 1991; 9:663-666.

9. Sauerwein M, Yamazaki T, Shimomura K. Hernandulcin in hairy root cultures of Lippia dulcis. Plant Cell Rep 1991a; 9:579-581.

10. Murashige T, Skoog F. A revised medium for rapid growth and bioassays with tobacco tissue cultures. Physiol Plant 1962; 15:473-497. 
11. Boustani A, Omidi M, Torabi S, Zarekarizi AR. Callus induction and plant regeneration in Lemon verbena (Lippia citrodora L.), an important medicinal plant. Trakia J Sci 2016; 1:30-38. doi: http://dx.doi.org/10.15547/tjs.2016.01.004

12. Juliani HR (Jr.), Koroch AR, Juliani HR, Trippi VS. Micropropagation of Lippia junelliana (Mold.) Tronc. Plant Cell Tissue Organ Cult 1999; 59:175-179. doi: http://dx.doi. org/10.1023/A:1006396531647

13. Castellanos-Hernandez OA, et al. In vitro clonal propagation and regeneration of the commercially important plant Mexican oregano (Lippia graveolens). In Vitro Cell Dev Biol - Plant 2013; 49(5):620-625. doi: http://dx.doi.org/10.1007/ s11627-013-95384

14. Servin C, Bruzzese D, Sapio OD, Gattuso M, Gatusso S. Evaluation of in vitro behavior of Aloysia citriodora Palau: Histological and chemical study. Mol Med Chem 2006; 11:19-20.

15. Peixoto $\mathrm{PH}$, et al. In vitro propagation of endangered Lippia filifolia Mart. and Schauer ex Schauer. In Vitro Cell Dev Biol - Plant 2006; 42(6):558-561. doi: http://dx.doi.org/10.1079/ IVP2006814

16. Giridhar P, Sowmya KS, Ramakrihna A, Ravishankar GA. Rapid clonal propagation and stevioside profiles of Stevia rebaudiana Bertoni. Int J Plant Dev Biol International 2010; 4(1):47-52.

17. Rani DN, Nair GM. Effects of plant growth regulators on high frequency shoot multiplication and callus regeneration of an important indian medicinal plant, Nirgundi (Vitex negundo L.). In Vitro Cell Dev Biol - Plant 2006; 42:69-73. doi: http://dx.doi.org/10.1079/IVP2005727
18. Bartnik C. Wpływ hydrożelu na przeżywalność siewek i sadzonek sosny pospolitej w warunkach suszy [The influence of hydrogel on the survival rate of plantlets and the plants of Pinus sylvestris L. during drought]. Studia i materiały centrum edukacji przyrodniczo-leśnej 2008; 10/2(18):329338 [in Polish].

19. El-Asmar J, Jaafar H, Bashour I, Farran MT, Saoud IP. Hydrogel banding improves plant growth, survival, and water use efficiency in two calcareous soils. Clean - Soil, Air, Water 2017; 45(7):1-9. doi: http://dx.doi.org/10.1002/clen.20170

20. Wang YT, Boogher CA. Effect of a medium-incorporated hydrogel on plant growth and water use of two foliage species. J Environ Hortic 1987; 5(3): 125-127.

21. Defaa C, Achour A, Mousadi AE, Msanda F. Effets de l'hydrogel sur la survie et la croissance des plantules d'arganier sur une parcelle de régénération en climat aride. JABS 2015; 92: 8586-8594. [in French] doi: http://dx.doi.org/10.4314/jab.v92i1.3

22. Montesano FF, Parente A, Santamaria P, Sannino A, Serio F. Biodegradable superabsorbent hydrogel increases water retention properties of growing media and plant growth. Agric Agric Sci Proc 2015; 4:451-458. doi: http://dx.doi.org/0.1016/j. aaspro.2015.03.052 